\title{
Thrombocytosis and hyperfibrinogenemia are predictive factors of clinical outcomes in high-grade serous ovarian cancer patients
}

Zheng Feng ${ }^{1,2+}$, Hao Wen ${ }^{1,2 \dagger}$, Rui Bi ${ }^{2,3}$, Yachen Duan ${ }^{1,2}$, Wentao Yang ${ }^{2,3}$ and Xiaohua Wu ${ }^{1,2^{*}}$

\begin{abstract}
Background: Over $20 \%$ of ovarian cancer patients have preoperative thrombocytosis or hyperfibrinogenemia. We aimed to demonstrate the clinical and prognostic significance of thrombocytosis and hyperfibrinogenemia in high-grade serous ovarian cancer (HGSC).

Methods: We retrospectively investigated HGSC patients who underwent primary staging or debulking surgery between April 2005 and June 2013 in our institution. None of these patients had received neoadjuvant chemotherapy. Data, including age, performance status, FIGO stage, serum CA125, platelet count, fibrinogen level, and surgical residual disease, were collected. Thrombocytosis was defined as a platelet count greater than $450 \times 10^{9} / \mathrm{L}$, and hyperfibrinogenemia was defined as a fibrinogen level higher than $4.00 \mathrm{~g} / \mathrm{L}$. Progression-free survival (PFS) and overall survival (OS) were analyzed with the Kaplan-Meier method and log-rank tests for univariate analyses. For the multivariate analyses, Cox regression analysis was used to evaluate the effects of the prognostic factors, which are expressed as hazard ratios (HRs).
\end{abstract}

Results: A total of 875 consecutive HGSC patients were identified. The median follow-up time was $29(1-115)$ months. The median (interquartile range, IQR) preoperative platelet count was $301(235-383) \times 10^{9} / \mathrm{L}$, and $121(13.8 \%)$ women had thrombocytosis. The median (IQR) preoperative fibrinogen level was 3.85 (3.19-4.45) g/L, and 332 (45.9\%) of the patients had hyperfibrinogenemia. Both preoperative thrombocytosis and hyperfibrinogenemia were associated with an advanced FIGO stage ( $p=0.008$ and $<0.001$, respectively), an increased CA125 level ( $p=0.004$ and 0.001 , respectively), more extensive ascites $(p<0.001$ and $<0.001$, respectively), more extensive residual disease $(p<0.001$ and $<0.001$, respectively) and chemosensitivity ( $p=0.043$ and $<0.001$, respectively). In the univariate analyses, hyperfibrinogenemia was associated with reduced PFS $(p<0.001)$ and OS $(p<0.001)$. However, thrombocytosis was not found to be a potential predictor of PFS $(P=0.098)$ or OS $(p=0.894)$. In the multivariate analyses, hyperfibrinogenemia was an independent predictor of OS $(p=0.014)$ but not PFS $(p=0.062)$.

Conclusion: Preoperative thrombocytosis and hyperfibrinogenemia reflected tumor burden to some extent and thus influenced treatment outcomes, and the fibrinogen level was found to be useful as a prognostic predictor in the HGSC patients.

Keywords: Ovarian cancer, Platelet, Fibrinogen, Tumor burden, Prognosis

\footnotetext{
* Correspondence: docwuxh@hotmail.com

${ }^{\dagger}$ Equal contributors

'Department of Gynecological Oncology, Fudan University Shanghai Cancer

Center, 270 Dong-an Road, Shanghai 200032, China

${ }^{2}$ Department of Oncology, Shanghai Medical College, Fudan University,

Shanghai 200032, China

Full list of author information is available at the end of the article
} 


\section{Background}

Ovarian cancer is the seventh most commonly diagnosed cancer and the eighth leading cause of cancer death among females worldwide. There were 238,700 estimated new cases and 151,900 deaths in 2012 [1]. Cancer patients often present in a prothrombotic state. Approximately 20 to $30 \%$ of ovarian cancer patients have preoperative thrombocytosis [2-4], and approximately $40 \%$ of patients have preoperative hyperfibrinogenemia $[5,6]$.

Serologic coagulation parameters, including platelet count and fibrinogen level, have emerged as potential preoperative predictors of clinical outcomes [3, 5, 7]. Several studies have shown that either thrombocytosis or hyperfibrinogenemia is associated with an advanced FIGO stage, more extensive residual disease, and poorer prognoses in ovarian cancer patients [2-4]. However, other studies have failed to draw similar conclusions $[8,9]$. The data are still insufficient to define the clinical and prognostic significance of platelet count and plasma fibrinogen level in ovarian cancer.

Furthermore, previous studies have shown that epithelial ovarian cancer is not a single disease but a group of heterogeneous tumors based on distinctive morphologic and molecular genetic features [10]. Previous research has failed to individually evaluate the clinical and prognostic values of platelet counts and fibrinogen levels according to histologic type. Because the vast majority of ovarian carcinomas are HGSC, the purpose of our study was to investigate the clinical and prognostic significance of the preoperative platelet count and fibrinogen level in a large mono-institutional study of Chinese patients with HGSC.

\section{Methods}

\section{Clinical data}

The clinical data were collected retrospectively from women who underwent primary staging or debulking surgery for HGSC between April 2005 and June 2013 at Fudan University Shanghai Cancer Center. This study was approved by the ethics committee of Fudan University Shanghai Cancer Center. All participants had provided written informed consent form. Patients were excluded if they had received neoadjuvant therapy, had been treated for recurrent disease, or were found to have other histological diagnoses on pathological review.

Clinical and pathological data were obtained from the medical records, cancer registries, and pathology reports. Patient characteristics including age, FIGO stage, preoperative laboratory data (CA125 level, platelet count, fibrinogen level), presence of ascites, surgical outcomes (R0, R1 vs R2), date of surgery, date of progression or recurrence, date of last follow-up, and the patient's disease status at last contact, were collected.
The histological diagnoses were based on the WHO criteria, and all microscopic slides were reviewed by two experienced gynecologic pathologists. Eight hundred seventy-five consecutive patients were identified, and all of the patients were followed up until December 31st, 2014.

Thrombocytosis was defined as platelet count greater than $450 \times 10^{9} / \mathrm{L}$. Hyperfibrinogenemia was defined as fibrinogen level greater than $4.00 \mathrm{~g} / \mathrm{L}$. R0 was defined as the absence of macroscopic residual disease (RD) after surgery. R1 was defined as a maximal diameter of the macroscopic residual disease after cytoreduction of $<1 \mathrm{~cm}$. $\mathrm{R} 2$ was defined as a maximal diameter of residual disease of $\geq 1 \mathrm{~cm}$. The optimal surgery was defined as the combination of R0 and R1. Chemosensitivity was defined as a time interval of 6 months or longer between the completion of platinum-based chemotherapy and the detection of relapse. Chemoresistance was defined as disease progression during adjuvant chemotherapy or within the 6month interval between the completion of platinumbased chemotherapy and the detection of relapse.

Progression-free survival (PFS) was defined as the time interval from the date of primary surgery to the date of disease progression or recurrence. Overall survival (OS) was defined as the time interval from the date of the primary surgery to the date of death or the last follow-up.

\section{Statistical analyses}

SPSS statistical software (version 21.0, SPSS, IBM Inc, New York, USA) was used for the statistical analyses. Descriptive statistics were used for the demographic data and are summarized as the means with the standard deviations (SD), the medians with the interquartile ranges (IQRs) or ranges, or the frequencies with the percentages. The categorical data were compared with chi-square or Fisher's exact tests as appropriate. The PFS and OS were analyzed with the Kaplan-Meier method, and log-rank tests were used in the univariate analyses. For the multivariate analyses, Cox regression analysis was used to evaluate the effects of the prognostic factors, which are expressed as hazard ratios (HRs). $P<0.05$ was considered statistically significant, and all reported $P$ values were 2 -sided.

\section{Results}

Patient characteristics and their correlations with thrombocytosis and hyperfibrinogenemia

The patient characteristics are shown in Table 1. Among the 875 patients, 874 (99.9\%) had documented preoperative platelet counts and 724 (82.7 \%) had documented fibrinogen levels. The median (IQR) platelet count was $3.85(3.19-4.45) \times 10^{9} / \mathrm{L}$, and $121(13.8 \%)$ women had preoperative thrombocytosis. The median (IQR) fibrinogen level was 3.85 (3.19-4.45) g/L, and 332 (45.9\%) had preoperative hyperfibrinogenemia. Seventy- 
Table 1 Patient Characteristics $(n=875)$

\begin{tabular}{|c|c|c|c|}
\hline \multicolumn{2}{|c|}{ Age at diagnosis, median (range), years } & \multicolumn{2}{|c|}{$56(30-90)$} \\
\hline \multicolumn{2}{|c|}{ Follow-up time, median (range), months } & \multicolumn{2}{|c|}{$29(1-115)$} \\
\hline \multirow[t]{2}{*}{ Menopausal status } & Postmenopausal & 602 & $68.8 \%$ \\
\hline & Premenopausal & 273 & $31.2 \%$ \\
\hline \multirow[t]{3}{*}{ Vital status } & Died & 345 & $39.4 \%$ \\
\hline & Alive & 448 & $51.2 \%$ \\
\hline & Censored & 82 & $9.4 \%$ \\
\hline \multirow[t]{2}{*}{ Family history } & Yes & 230 & $26.3 \%$ \\
\hline & No & 643 & $73.7 \%$ \\
\hline \multirow[t]{2}{*}{ CA125 level } & $<500 \mathrm{U} / \mathrm{ml}$ & 193 & $22.6 \%$ \\
\hline & $\geq 500 \mathrm{U} / \mathrm{ml}$ & 662 & $77.4 \%$ \\
\hline \multirow[t]{3}{*}{ Ascites } & No & 99 & $11.3 \%$ \\
\hline & $<500 \mathrm{ml}$ & 146 & $16.7 \%$ \\
\hline & $\geq 500 \mathrm{ml}$ & 629 & $72.0 \%$ \\
\hline \multirow[t]{2}{*}{ FIGO Stage } & Early $(I, I)$ & 75 & $8.6 \%$ \\
\hline & Advanced (III, IV) & 800 & $91.4 \%$ \\
\hline \multirow[t]{3}{*}{ Cytoreduction } & RO & 272 & $31.1 \%$ \\
\hline & $\mathrm{R} 1$ & 434 & $49.6 \%$ \\
\hline & $\mathrm{R} 2$ & 169 & $19.3 \%$ \\
\hline \multirow[t]{3}{*}{ Chemosensitivity } & Yes & 568 & $66.9 \%$ \\
\hline & No & 237 & $27.9 \%$ \\
\hline & NA & 44 & $5.2 \%$ \\
\hline \multicolumn{2}{|c|}{ Platelet count (median, IQR) $\left(\times 10^{9} / \mathrm{L}\right)$} & \multicolumn{2}{|c|}{$301(235-383)$} \\
\hline \multirow[t]{2}{*}{ Thrombocytosis } & Yes & 121 & $13.8 \%$ \\
\hline & No & 753 & $86.2 \%$ \\
\hline \multicolumn{2}{|c|}{ Fibrinogen level (median, IQR)(g/L) } & \multicolumn{2}{|c|}{$3.85(3.19-4.45)$} \\
\hline \multirow[t]{2}{*}{ Hyperfibrinogenemia } & Yes & 332 & $45.9 \%$ \\
\hline & No & 392 & $54.1 \%$ \\
\hline
\end{tabular}

seven patients had coexisting thrombocytosis and hyperfibrinogenemia. Seventy-five $(8.6 \%)$ patients were early stage (I-II) and 800 (91.4\%) were advanced stage (III-IV).

The correlations of the clinical characteristics with preoperative thrombocytosis and hyperfibrinogenemia are summarized in Tables 2 and 3, respectively. Both preoperative thrombocytosis and hyperfibrinogenemia were associated with an advanced FIGO stage $(p=0.008$ and $<0.001$, respectively), an increased CA125 level $(p=0.004$ and 0.001 , respectively) and more extensive ascites $(p<0.001$ and $<0.001$, respectively). There were no significant correlations of age with thrombocytosis or hyperfibrinogenemia ( $p=0.493$ and 0.117 , respectively).

Treatment outcomes, survival analysis, and their correlations with thrombocytosis and hyperfibrinogenemia

After primary surgery, $272(31.1 \%)$ of the patients were debulked to R0, and 434 (49.6\%) were debulked to $<1 \mathrm{~cm}$ with macroscopic disease (R1). As the extent of residual disease increased, the numbers of patients who presented with thrombocytosis (R0, R1, and R2: $6.6 \%, 15.4 \%$, $21.3 \%$, respectively, $p<0.001$ ) and hyperfibrinogenemia $(30.3 \%, 50.0 \%, 61.5 \%$, respectively, $p<0.001)$ increased. Pairwise comparisons revealed significant differences in the prevalences of hyperfibrinogenemia between the R0, $\mathrm{R} 1$ and R2 groups (R0 vs R1: $p<0.001, \mathrm{R} 0$ vs R2: $p<0.001$, $\mathrm{R} 1$ vs R2: $p=0.026)$. Regarding the platelet counts, a smaller proportion of the patients in the R0 group had thrombocytosis compared with the $\mathrm{R} 1$ and $\mathrm{R} 2$ groups (R0 vs R1: $p=0.001$ and R0 vs R2: $p<0.001$ ). However, the difference in the prevalence of thrombocytosis between the R1 and R2 groups was not significant $(p=0.092)$.

Following primary surgery, 849 (97.0 \%) patients had received platinum-based adjuvant chemotherapy. Among these patients, 568 (66.9 \%) were chemosensitive (Table 1). Greater proportions of the patients with chemoresistant disease had documented thrombocytosis (17.7\% vs $12.2 \%, p=0.043)$ and hyperfibrinogenemia $(59.5 \%$ vs $39.2 \%, p<0.001)$ compared with the chemosensitive patients. Next, we investigated the correlations of chemosensitivity with thrombocytosis and hyperfibrinogenemia after stratification according to surgical outcome. The prevalence of thrombocytosis was no longer associated with chemosensitivity in the R0, R1 or R2 subgroups $\left(p_{R 0}=0.744, p_{R 1}=0.660\right.$, and $\left.p_{R 2}=0.228\right)$. Regarding the fibrinogen levels, greater proportions of chemosensitive patients in the R0 and R1 groups had hyperfibrinogenemia compared with the corresponding chemoresistant patients $\left(\mathrm{p}_{\mathrm{R} 0}=0.001\right.$ and $\left.\mathrm{p}_{\mathrm{R} 1}=0.004\right)$. However, the difference in hyperfibrinogenemia between the chemosensitive and chemoresistant patients was not significant in the R2 group $(p=1.000)$.

The median(range) follow-up time was 29 (1-115) months. One hundred four (11.9\%) women experienced disease progression during adjuvant chemotherapy, 499 (57.0 \%) patients exhibited documented recurrence, and 345 (39.4 \%) deaths were documented. The median (95 \% CI) PFS was 18 (16.8-19.2) months, and the 2year and 5-year PFSs were 38.1 and $19.4 \%$, respectively. The median (95\% CI) OS was 58 (51.4-64.6) months, and the 2-year and 5-year OSs were 79.3 and $48.8 \%$, respectively.

Regarding PFS and OS, the known negative influences of advanced FIGO stage $(p<0.001$ and $<0.001$, respectively), the presence of residual disease (R0 vs $\mathrm{R} 1+\mathrm{R} 2: p<0.001$ and $<0.001$, respectively), and chemoresistance $(p<0.001$ and $<0.001$, respectively) were confirmed in the univariate analyses.

In the univariate analysis, preoperative hyperfibrinogenemia was associated with impaired PFS (15.0 (13.8-16.2) vs 21.0 (17.8-24.2) months, $p<0.001$, Fig. 1a). The women with thrombocytosis tended to exhibit shorter PFSs than 
Table 2 Clinicopathologic parameters of the patients and thrombocytosis

\begin{tabular}{|c|c|c|c|c|}
\hline \multirow[t]{2}{*}{ Parameters } & & \multicolumn{2}{|c|}{ Thrombocytosis } & \multirow[t]{2}{*}{$P$-value } \\
\hline & & Yes & No & \\
\hline \multirow[t]{2}{*}{ Age } & $<56(427)$ & $63(14.8 \%)$ & $364(85.2 \%)$ & \multirow[t]{2}{*}{0.493} \\
\hline & $\geq 56(447)$ & $58(13.0 \%)$ & 389(87.0 \%) & \\
\hline \multirow[t]{2}{*}{ FIGO Stage } & Early(74) & $3(4.1 \%)$ & $71(95.9 \%)$ & \multirow[t]{2}{*}{0.008} \\
\hline & Advanced(800) & $118(14.8 \%)$ & $682(85.2 \%)$ & \\
\hline \multirow[t]{2}{*}{ CA125 Level } & $<500$ U/ml(193) & $15(7.8 \%)$ & 178(92.2 \%) & \multirow[t]{2}{*}{0.004} \\
\hline & $\geq 500 \mathrm{U} / \mathrm{ml}(661)$ & 103(15.6\%) & $558(84.4 \%)$ & \\
\hline \multirow[t]{2}{*}{ Hyperfibrinogenemia } & Yes (332) & $77(23.2 \%)$ & $255(76.8 \%)$ & \multirow[t]{2}{*}{$<0.001$} \\
\hline & No (391) & 15(3.8\%) & $376(96.2 \%)$ & \\
\hline \multirow[t]{3}{*}{ Ascites $^{a}$} & No (99) & $3(3.0 \%)$ & $96(97.0 \%)$ & \multirow[t]{3}{*}{$<0.001$} \\
\hline & $<500 \mathrm{ml}(146)$ & $5(3.4 \%)$ & $141(96.6 \%)$ & \\
\hline & $\geq 500 \mathrm{ml}(628)$ & $113(18.0 \%)$ & $515(82.0 \%)$ & \\
\hline \multirow[t]{3}{*}{ Cytoreduction $^{\mathrm{b}}$} & $\mathrm{RO}(271)$ & 18(6.6 \%) & 253(93.4 \%) & \multirow[t]{3}{*}{$<0.001$} \\
\hline & R1 (434) & $67(15.4 \%)$ & $367(84.6 \%)$ & \\
\hline & R2(169) & $36(21.3 \%)$ & 133(78.7 \%) & \\
\hline \multirow[t]{2}{*}{ Chemosensitivity } & Yes (567) & $69(12.2 \%)$ & 498(87.8 \%) & \multirow[t]{2}{*}{0.043} \\
\hline & No (237) & $42(17.7 \%)$ & 195(82.3\%) & \\
\hline
\end{tabular}

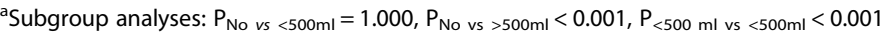

${ }^{b}$ Subgroup analyses: $P_{R 0}$ vs $R 1=0.001, P_{R 0}$ vs R2 $<0.001, P_{R 1}$ vs $R 2=0.092$

those with normal platelet counts; however, this difference was not significant (17.0 (14.1-19.9) vs 19.0 (17.5-20.5) months, respectively, $p=0.098$; Fig. 1b). In the multivariate analysis with adjustments for age, FIGO stage, cytoreduction outcome and chemosensitivity status, preoperative

Table 3 Clinicopathologic parameters of the patients and hyperfibrinogenemia

\begin{tabular}{|c|c|c|c|c|}
\hline \multirow[t]{2}{*}{ Parameters } & & \multicolumn{2}{|c|}{ Hyperfibrinogenemia } & \multirow[t]{2}{*}{$P$-value } \\
\hline & & Yes & No & \\
\hline \multirow[t]{2}{*}{ Age } & $<56(362)$ & $177(48.9 \%)$ & $185(51.1 \%)$ & 0.117 \\
\hline & $\geq 56(362)$ & $155(42.8 \%)$ & $207(57.2 \%)$ & \\
\hline \multirow[t]{2}{*}{ FIGO Stage } & Early(62) & $12(19.4 \%)$ & $50(80.6 \%)$ & $<0.001$ \\
\hline & Advanced(662) & $320(48.3 \%)$ & $342(51.7 \%)$ & \\
\hline \multirow[t]{2}{*}{ CA125 Level } & $<500 \mathrm{U} / \mathrm{ml}(157)$ & $53(33.8 \%)$ & $104(66.2 \%)$ & 0.001 \\
\hline & $\geq 500 \mathrm{U} / \mathrm{ml}(556)$ & $272(48.9 \%)$ & $284(51.1 \%)$ & \\
\hline \multirow[t]{3}{*}{ Ascites $^{a}$} & $\mathrm{No}(85)$ & $21(24.7 \%)$ & $64(75.3 \%)$ & $<0.001$ \\
\hline & $<500 \mathrm{ml}(122)$ & $22(18.0 \%)$ & $100(82.0 \%)$ & \\
\hline & $\geq 500 \mathrm{ml}(723)$ & $289(56.0 \%)$ & $227(44.0 \%)$ & \\
\hline \multirow[t]{3}{*}{ Cytoreduction $^{\mathrm{b}}$} & $\mathrm{RO}(231)$ & 70(30.3 \%) & $161(69.7 \%)$ & $<0.001$ \\
\hline & R1(358) & $179(50.0 \%)$ & $179(50.0 \%)$ & \\
\hline & R2(135) & $83(61.5 \%)$ & $52(38.5 \%)$ & \\
\hline \multirow[t]{2}{*}{ Chemosensitivity } & Yes(474) & $186(39.2 \%)$ & $288(60.8 \%)$ & $<0.001$ \\
\hline & $\mathrm{No}(197)$ & $118(59.5 \%)$ & 79(40.1\%) & \\
\hline
\end{tabular}

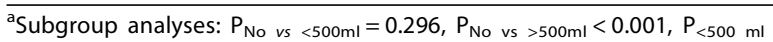
vs $<500 \mathrm{ml}<0.001$

Subgroup analyses: $\mathrm{P}_{\mathrm{R} 0 \text { vs } R 1}<0.001, \mathrm{P}_{\mathrm{R} 0 \text { vs } \mathrm{R} 2}<0.001, \mathrm{P}_{\mathrm{R} 1 \text { vs } \mathrm{R} 2}=0.026$ hyperfibrinogenemia was not found to be independent predictor of PFS $(\mathrm{HR}=1.202$, $95 \% \mathrm{CI}, 0.991-1.459$, $p=0.062$; Table 4).

Hyperfibrinogenemia was associated with a shorter OS (42 (35.2-48.8) vs $72(58.5-85.5)$ months, $p<0.001)$ in the univariate analysis, but thrombocytosis was not correlated with OS (54.0 (41.0-67.0) vs 58.0 (50.6-65.4) months, $p=0.894$; Fig. 2). In the multivariate analysis with adjustments for age, FIGO stage, cytoreduction outcome and chemosensitivity status, hyperfibrinogenemia was independently associated with a poorer OS $(\mathrm{HR}=1.523,95 \%$ CI, 1.179-1.967, $p=0.001$; Table 5).

\section{Discussion}

In this large mono-institutional study, we demonstrated that both thrombocytosis and hyperfibrinogenemia were associated with clinicopathological characteristics and treatment outcomes. Additionally, hyperfibrinogenemia was correlated with poorer overall survival in the Chinese patients with HGSC.

We found that both thrombocytosis and hyperfibrinogenemia were associated with increased tumor stage, elevated CA125 level, and more extensive ascites. These finding are in accordance with the previous published data from patients with epithelial ovarian cancer regardless of histologic type $[2-5,11]$, indicating that the platelet and fibrinogen levels seem to increase in parallel with tumor progression and metastasis. Experimental studies have proven that a hypercoagulable status can be 

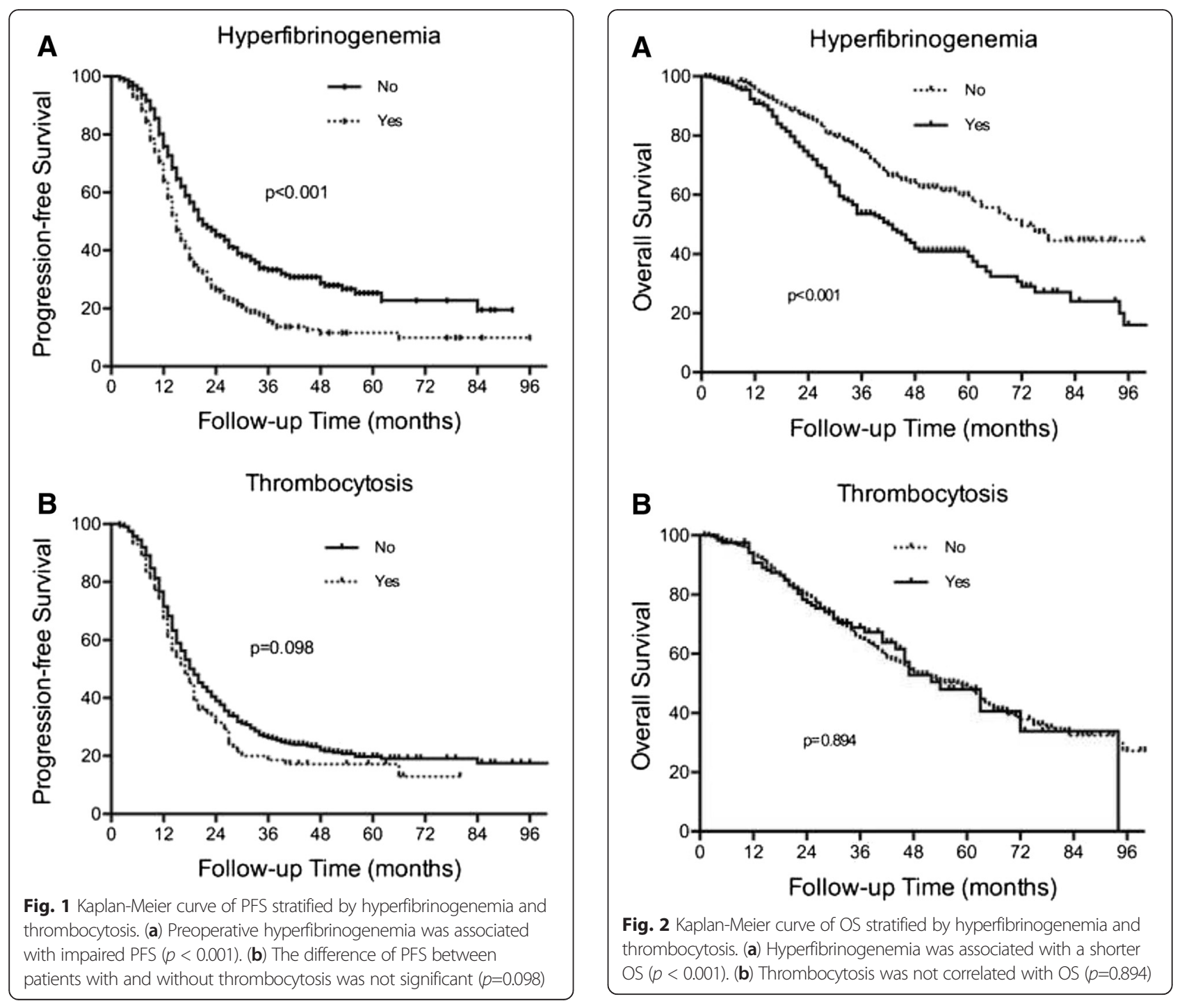

Table 4 Multivariable analysis of the factors associated with PFS

\begin{tabular}{|c|c|c|c|c|c|c|}
\hline \multirow{2}{*}{\multicolumn{2}{|c|}{$\begin{array}{l}\text { Characteristics } \\
\text { Age (as a continuous variable) }\end{array}$}} & \multirow{3}{*}{$\begin{array}{l}\text { HR } \\
1.006 \\
\text { Referer }\end{array}$} & \multicolumn{3}{|c|}{$95 \% \mathrm{Cl}$} & \multirow{3}{*}{$\begin{array}{l}P \text { value } \\
0.263\end{array}$} \\
\hline & & & 0.996 & - & 1.016 & \\
\hline \multirow[t]{2}{*}{ FIGO Stage } & Early & & & & & \\
\hline & Advanced & 2.162 & 1.367 & - & 3.417 & 0.001 \\
\hline \multirow[t]{3}{*}{ Cytoreduction } & Ro & Referer & & & & \\
\hline & R1 & 1.266 & 1.001 & - & 1.603 & 0.049 \\
\hline & $\mathrm{R} 2$ & 1.407 & 1.047 & - & 1.890 & 0.023 \\
\hline \multirow[t]{2}{*}{ Chemosensitivity } & No & Referer & & & & \\
\hline & Yes & 0.083 & 0.065 & - & 0.107 & $<0.001$ \\
\hline \multirow[t]{2}{*}{ Hyperfibrinogenemia } & No & Referer & & & & \\
\hline & Yes & 1.202 & 0.991 & - & 1.459 & 0.062 \\
\hline
\end{tabular}

Table 5 Multivariable analysis of the factors associated with OS

\begin{tabular}{|c|c|c|c|c|c|c|}
\hline \multirow{2}{*}{\multicolumn{2}{|c|}{$\begin{array}{l}\text { Characteristics } \\
\text { Age (as a continuous variable) }\end{array}$}} & \multirow{3}{*}{$\begin{array}{l}\text { HR } \\
1.021 \\
\text { Referen }\end{array}$} & \multicolumn{3}{|c|}{$95 \% \mathrm{Cl}$} & \multirow{2}{*}{$\begin{array}{l}P \text { value } \\
0.005\end{array}$} \\
\hline & & & 1.006 & - & 1.036 & \\
\hline \multirow[t]{2}{*}{ FIGO Stage } & Early & & & & & \\
\hline & Advanced & 3.574 & 1.522 & - & 8.393 & 0.003 \\
\hline \multirow[t]{3}{*}{ Cytoreduction } & Ro & Refere & & & & \\
\hline & R1 & 1.518 & 1.060 & - & 2.175 & 0.023 \\
\hline & R2 & 1.412 & 0.929 & - & 2.147 & 0.107 \\
\hline \multirow[t]{2}{*}{ Chemosensitivity } & No & Refere & & & & \\
\hline & Yes & 0.193 & 0.146 & - & 0.255 & $<0.001$ \\
\hline \multirow[t]{2}{*}{ Hyperfibrinogenemia } & No & Refere & & & & \\
\hline & Yes & 1.413 & 1.074 & - & 1.859 & 0.014 \\
\hline
\end{tabular}


induced directly by the tumor cells themselves or indirectly by the tumor-associated cytokines that are produced by host macrophages or endothelial cells [2, 12, 13], and interleukin-6 (IL-6) has been found to be a key regulator of paraneoplastic thrombocytosis and hyperfibrinogenemia $[2,12-15]$. Consequently, we believe that coagulation parameters could reflect tumor burden to some extent. Additionally, IL-6-targeted therapy has been found to be capable benefiting the treatment of ovarian cancer [2, 16, 17].

Because they were correlated with increased disease burden, platelet count and plasma fibrinogen level could be considered to be predictors of surgical outcomes $[2-6,16]$. $\mathrm{Ma}$ et al. [4] found that epithelial ovarian cancer patients with thrombocytosis have a greater likelihood of suboptimal cytoreduction $(p=0.035)$. Another multicenter study reported that an elevated fibrinogen level is associated with the presence of increased postoperative residual tumor mass $(p<0.001)$, which might be due to the increased operative complexity that results from increased tumor burden. Our study confirmed that both thrombocytosis and hyperfibrinogenemia were correlated with more extensive post-surgical residual disease.

Additionally, we investigated the relationship between hypercoagulability and chemosensitivity in HGSC patients for the first time. We observed that more patients with chemoresistant disease had documented thrombocytosis and hyperfibrinogenemia compared with the chemosensitive patients. Previous studies have demonstrated that coagulation system components can promote tumor growth, angiogenesis, and metastasis and thus interact with cytotoxic drugs $[12,13,18-21]$. The response to chemotherapy can be influenced by surgical residual disease, and we have proven that hypercoagulability was associated with more extensive residual disease. Therefore, we investigated the correlation between hypercoagulability and chemosensitivity following stratification by postsurgical residual disease. We found that only hyperfibrinogenemia was associated with chemosensitivity in the R0 and R1 groups and that thrombocytosis was no longer a predictor of chemotherapy response.

Several previous studies have also shown that platelet count and fibrinogen level are potential prognostic indicators in ovarian cancer patients $[2-6,11]$. Once activated, the coagulation system can directly or indirectly promote disease progression and metastasis and thus lead to poorer prognosis [13, 19-22]. Consequently, we confirmed that hyperfibrinogenemia was an independent predictor of poorer OS in HGSC patients; however, we failed to demonstrate the prognostic significance of thrombocytosis. Allensworth et al. [3] proved that thrombocytosis is an independent predictor of PFS but not OS; however, when these authors stratified the patients according to FIGO stage, they found that thrombocytosis was no longer an independent predictor of PFS in the advanced stage (HR $=1.31,0.99-1.75)$. Perhaps because the overwhelming majority (91.4 \%) of our patients were in the advanced stage, no differences according to thrombocytosis were observed in our study.

The limitation of our study is that it was a retrospective study that depended on accurate documentation, and thus the potential for recall bias existed. Additionally, our center is one of the tertiary referral hospitals in China, and over $90 \%$ of patients in such hospitals have advanced disease. Previous studies have shown that other coagulation biomarkers, including D-dimer and von Willebrand factor, can also reflect disease burden and serve as prognostic predictors [7, 8]. However, these parameters are not routinely examined in our daily work.

Notwithstanding its limitation, this was a monoinstitutional retrospective study that included a large number of HGSC patients. This study involved a group of homogenous patients with the same histology who were treated within 9 years and underwent similar surgical procedures and consistent platinum-based chemotherapy regimens. And this could increase the generalizability of our study findings.

\section{Conclusion}

In conclusion, our study suggests that both preoperative thrombocytosis and hyperfibrinogenemia reflect tumor burden to some extent and thus are predictive factors of treatment outcomes and that fibrinogen level could be regarded as a prognostic predictor in HGSC patients.

\section{Abbreviations}

HGSC: high-grade serous ovarian cancer; PFS: progression-free survival; OS: overall survival; HRs: hazard ratios; RD: residual disease; SD: standard deviations; IQRs: interquartile ranges.

\section{Competing interests}

The authors declare that they have no competing interests.

\section{Authors' contributions}

ZF and HW participated in the study design, carried out the data collection, performed the statistical analysis, and drafted the manuscript. RB and WTY participated in the pathologic review of all slides. YCD carried out the data collection. XHW conceived of the study, and participated in its design and coordination. All authors read and approved the final manuscript.

\section{Acknowledgement}

This work was supported by a key project of Science and Technology Commission of Shanghai Municipality (12411950300) to XH Wu.

\section{Author details}

${ }^{1}$ Department of Gynecological Oncology, Fudan University Shanghai Cancer Center, 270 Dong-an Road, Shanghai 200032, China. ${ }^{2}$ Department of Oncology, Shanghai Medical College, Fudan University, Shanghai 200032, China. ${ }^{3}$ Department of Pathology, Fudan University Shanghai Cancer Center, Shanghai 200032, China.

Received: 28 August 2015 Accepted: 18 January 2016

Published online: 27 January 2016 


\section{References}

1. Torre LA, Bray F, Siegel RL, Ferlay J, Lortet-Tieulent J, Jemal A. Global cancer statistics, 2012. CA Cancer J Clin. 2015;65(2):87-108.

2. Stone RL, Nick AM, McNeish IA, Balkwill F, Han HD, Bottsford-Miller J, et al. Paraneoplastic Thrombocytosis in Ovarian Cancer. N Engl J Med. 2012 366(7):610-8.

3. Allensworth SK, Langstraat CL, Martin JR, Lemens MA, McGree ME, Weaver AL, et al. Evaluating the prognostic significance of preoperative thrombocytosis in epithelial ovarian cancer. Gynecol Oncol. 2013;130(3):499-504.

4. Ma X, Wang Y, Sheng H, Tian W, Qi Z, Teng F, et al. Prognostic significance of thrombocytosis, platelet parameters and aggregation rates in epithelial ovarian cancer. J Obstet Gynaecol Res. 2014;40(1):178-83.

5. Qiu J, Yu Y, Fu Y, Ye F, Xie X, Lu W. Preoperative plasma fibrinogen, platelet count and prognosis in epithelial ovarian cancer. J Obstet Gynaecol Res. 2012:38(4):651-7.

6. Man YN, Wang YN, Hao J, Liu X, Liu C, Zhu C, et al. Pretreatment Plasma D-Dimer, Fibrinogen, and Platelet Levels Significantly Impact Prognosis in Patients With Epithelial Ovarian Cancer Independently of Venous Thromboembolism. Int J Gynecol Cancer. 2015;25(1):24-32.

7. Koh SCL, Khalil R, Lim FK, llancheran A, Choolani M. The association between fibrinogen, von Willebrand Factor, antithrombin III, and D-dimer levels and survival outcome by 36 months from ovarian cancer. Clin Appl Thromb Hemost. 2006;12(1):3-8.

8. Tas F, Kilic L, Bilgin E, Keskin S, Sen F, Ciftci R, et al. Clinical and prognostic significance of coagulation assays in advanced epithelial ovarian cancer. Int J Gynecol Cancer. 2013;23(2):276-81.

9. Koh SCL, Razvi K, Chan YH, Narasimhan K, llancheran A, Low JJ, et al. The association with age, human tissue kallikreins 6 and 10 and hemostatic markers for survival outcome from epithelial ovarian cancer. Arch Gynecol Obstet. 2011;284(1):183-90

10. Kurman RJ, Shih I-M. The Origin and Pathogenesis of Epithelial Ovarian Cancer: A Proposed Unifying Theory. Am J Surg Pathol. 2010;34(3):433-43.

11. Polterauer S, Grimm C, Seebacher V, Concin N, Marth C, Tomovski C, et al. Plasma Fibrinogen Levels and Prognosis in Patients with Ovarian Cancer: A Multicenter Study. Oncologist. 2009;14(10):979-85.

12. Wang X, Wang E, Kavanagh JJ, Freedman RS. Ovarian cancer, the coagulation pathway, and inflammation. J Transl Med. 2005;3:25.

13. Kolodziejczyk J, Ponczek MB. The role of fibrinogen, fibrin and fibrin(ogen) degradation products (FDPs) in tumor progression. Contemp Oncol (Pozn). 2013;17(2):113-9.

14. Bode JG, Albrecht U, Haeussinger D, Heinrich PC, Schaper F. Hepatic acute phase proteins - Regulation by IL-6-and IL-1-type cytokines involving STAT3 and its crosstalk with NF-kappa B-dependent signaling. Eur J Cell Biol. 2012; 91(6-7):496-505.

15. Albrecht U, Yang X, Asselta R, Keitel V, Tenchini ML, Ludwig S, et al. Activation of NF-kappa B by IL-1 beta blocks IL-6-induced sustained STAT3 activation and STAT3-dependent gene expression of the human gammafibrinogen gene. Cell Signal. 2007:19(9):1866-78.

16. Coward J, Kulbe H, Chakravarty P, Leader D, Vassileva V, Leinster DA, et al. Interleukin-6 as a therapeutic target in human ovarian cancer. Clin Cancer Res. 2011;17(18):6083-96.

17. Lo CW, Chen MW, Hsiao M, Wang S, Chen CA, Hsiao SM, et al. IL-6 trans-signaling in formation and progression of malignant ascites in ovarian cancer. Cancer Res. 2011;71(2):424-34.

18. Egan K, Crowley D, Smyth P, OToole S, Spillane C, Martin C, et al. Platelet Adhesion and Degranulation Induce Pro-Survival and Pro-Angiogenic Signalling in Ovarian Cancer Cells. PLoS One. 2011;6(10):e26125.

19. Labelle M, Begum S, Hynes RO. Direct Signaling between Platelets and Cancer Cells Induces an Epithelial-Mesenchymal-Like Transition and Promotes Metastasis. Cancer Cell. 2011;20(5):576-90.

20. Palumbo JS, Potter JM, Kaplan LS, Talmage K, Jackson DG, Degen JL. Spontaneous hematogenous and lymphatic metastasis, but not primary tumor growth or angiogenesis, is diminished in fibrinogen-deficient mice. Cancer Res. 2002;62(23):6966-72.

21. Gay LI, Felding-Habermann B. Contribution of platelets to tumour metastasis. Nat Rev Cancer. 2011;11(2):123-34.

22. Goubran HA, Burnouf T, Radosevic M, El-Ekiaby M. The platelet-cancer loop. Eur J Intern Med. 2013;24(5):393-400

\section{Submit your next manuscript to BioMed Central and we will help you at every step:}

- We accept pre-submission inquiries

- Our selector tool helps you to find the most relevant journal

- We provide round the clock customer support

- Convenient online submission

- Thorough peer review

- Inclusion in PubMed and all major indexing services

- Maximum visibility for your research

Submit your manuscript at www.biomedcentral.com/submit
Biomed Central 